\title{
Open Cardiac Surgery without Blood and Blood Products Transplantation
}

\author{
Mehmet Kaplan, MD, ${ }^{1}$ Tolga Can, MD, ${ }^{1}$ Anil Karaagac, MD,${ }^{1}$ Murat Acarel, $\mathrm{MD},{ }^{2}$ Adlan Olsun, MD, ${ }^{1}$ \\ M. Inanc Yesilkaya, MD, ${ }^{1}$ Hakki Aydogan, $\mathrm{MD}^{1}$ \\ ${ }^{1}$ Cardiovascular Surgery Clinic and ${ }^{2}$ Anesthesiology and Reanimation Clinic, Dr. Siyami Ersek Thoracic and Cardiovascular \\ Surgery Training and Research Hospital, Istanbul, Turkey
}

\section{ABSTRACT}

Background: Blood transfusions are the most common type of tissue and organ transplantation. Perioperative and postoperative transfusions may cause morbidity and mortality and transfusion should based on only hematocrit values but also on hemodynamic and clinical parameters of the patient, which cannot be ignored.

Methods: A prospective study was conducted between January 2015 and October 2016 with adult patients undergoing elective open heart surgery. In these patients, a protocol was established, and patients were divided into two groups as transfusion (-) and transfusion (+). In the first 24 hours in the intensive care unit, patients' drainage, 24-hours urine output, awakening and extubation times, and lactate and bilirubin levels in arterial blood gases were recorded. Thirty-day mortality and morbidity, and hemodynamic and clinical data were compared between these two groups.

Results: We have performed a total of 138 cases; no blood and blood products were transfused in $71 \%(\mathrm{n}=98)$, and in $29.0 \%(n=40)$ blood and blood products were transfused. Thirty-day mortality and morbidity (arrhythmia, infectious and pulmonary morbidity, myocardial infarction, cerebrovascular accident, renal dysfunction, sternal revision) were compared between these two groups and no statistically significant difference was observed. Patients' awakening, extubation time, cardiopulmonary bypass period, cross-clamp time, and days in intensive care unit and hospital were compared, and there was no statistically significant difference between the two groups.

Conclusion: In this study, we conclude that open heart surgery without blood transfusion may be accomplished with decent peri/postoperative management. The patients who did not receive any blood or blood products were not compromised clinically or hemodynamically. No extra morbidity and mortality were seen in the non-transfusion group. Transfusion decision was based on clinical and hemodynamic parameters such as persistent hypotension or tachycardia, hyperlactatemia, low urine output, and anemic symptoms.

Received August 22, 2017; received in revised form October 3, 2017; accepted October 4, 2017

Correspondence: Mehmet Kaplan, MD, Assoc Prof, Siyami Ersek Thoracic and Cardiovascular Surgery Training and Research Hospital, Tibbiye Cad, No: 25/2, Haydarpasa, 34668 Uskudar, Istanbul, Turkey; +902165424464 (e-mail: drmebmetkaplan@gmail.com).

\section{INTRODUCTION}

Perioperative and postoperative anemia is frequently seen in cardiac surgery and mostly cured by transfusion. Hemodilution in open heart surgery causes anemia perioperatively and postoperatively. Paying attention only to hematocrit and hemoglobin values but not the clinical condition of patients leads to unnecessary blood and blood product transfusions, which may cause morbidity (especially increase in infection and acute kidney injury rates) and mortality [Murphy 2007; Koch 2006]. Transfusion-related problems, like storage conditions and storage time of blood and blood products as well as subgroup incompatibilities [Koch 2008] are also important reasons for complications. On the other hand, to avoid tissue hypoxia caused by perioperative and postoperative bleeding, higher hemoglobin levels are targeted, particularly in elderly patients [Pulido 2015]. That is the main problem in making the decision for transfusion.

Blood transfusions are the most common type of tissue and organ transplantation. Suitable management of these transfusions is one of the most important factors that directly affect the outcomes of open heart surgery. Recent guidelines about transfusion in cardiac surgery, which is called restrictive transfusion, proposes restricting the use of blood and blood products [Patel 2015].

We included patients that were operated between January 2015 and October 2016 in this prospective study. Cases were divided into two groups according to whether they were transfused or not. We aimed to show that open heart surgery can be done without blood transfusion in a wide variety of cases.

\section{METHODS}

\section{Study Population}

The study was conducted prospectively between January 2015 and October 2016. Demographic features of the cases were age, sex, weight, height, and body mass index (BMI). $80.4 \%(\mathrm{n}=111)$ of patients were male; $19.6 \%$ $(n=27)$ of patients were female, making a total number of 138 cases. Cases were divided into two groups as transfusion (-) $(\mathrm{n}=98)$ and transfusion $(+)(\mathrm{n}=40)$. Besides the presence of diabetes, smoking history, hypertension, data showing organ dysfunction (blood urea nitrogen [BUN], creatinine, serum electrolyte levels, liver function tests), pulmonary function test results, preoperative hematocrit and hemoglobin values, and left ventricular ejection fraction values were also analyzed (Table 1). Types of cases are shown in Table 2. 
Table 1. Evaluation of Demographic and Preoperative Characteristics of Patients

\begin{tabular}{|c|c|c|c|}
\hline & $\begin{array}{c}\text { Transfusion }\left(^{+}\right) \\
(n=40)\end{array}$ & $\begin{array}{c}\text { Transfusion }(-) \\
(\mathrm{n}=98)\end{array}$ & $P$ \\
\hline \multicolumn{4}{|l|}{ Age, $y$} \\
\hline Mean \pm SD & $60.7 \pm 11.02$ & $59.3 \pm 9.4$ & $.458 \ddagger$ \\
\hline Min-Max (Median) & $25-77(61)$ & $25-78(60)$ & \\
\hline \multicolumn{4}{|l|}{ Sex } \\
\hline Male & $29(72.5)$ & $82(83.7)$ & $.206 \S$ \\
\hline Female & $11(27.5)$ & $16(16.3)$ & \\
\hline \multicolumn{4}{|l|}{ Weight, kg } \\
\hline Mean \pm SD & $77.6 \pm 14.5$ & $80.4 \pm 11.5$ & $.282 \ddagger$ \\
\hline Min-Max (Median) & $40-109$ (78) & $58-120(80)$ & \\
\hline \multicolumn{4}{|l|}{ Height, (m) } \\
\hline Mean \pm SD & $1.7 \pm 0.1$ & $1.7 \pm 0.08$ & $.032 \ddagger^{*}$ \\
\hline Min-Max (Median) & $1.5-1.8(1.7)$ & $1.5-1.9(1.7)$ & \\
\hline \multicolumn{4}{|l|}{$\mathrm{BMI}, \mathrm{kg} / \mathrm{m}^{2}$} \\
\hline Mean \pm SD & $28.0 \pm 4.6$ & $27.9 \pm 3.9$ & $.945 \ddagger$ \\
\hline Min-Max (Median) & $17.8-40(27.1)$ & $20.1-39.2(27.5)$ & \\
\hline \multicolumn{4}{|l|}{ Diabetes mellitus } \\
\hline No & $19(47.5)$ & $57(58.2)$ & $.340 \S$ \\
\hline Yes & $21(52.5)$ & $41(41.8)$ & \\
\hline \multicolumn{4}{|l|}{ Hypertension } \\
\hline No & $19(47.5)$ & $50(51.0)$ & $.851 \S$ \\
\hline Yes & $21(52.5)$ & $48(49.0)$ & \\
\hline \multicolumn{4}{|l|}{ Liver disease } \\
\hline No & $37(92.5)$ & $87(88.8)$ & .757 \\
\hline Yes & $3(7.5)$ & $11(11.2)$ & \\
\hline \multicolumn{4}{|l|}{ LVEF, \% } \\
\hline Mean \pm SD & $50.7 \pm 10.2$ & $51.8 \pm 9.9$ & $.527 \ddagger$ \\
\hline Min-Max (Median) & $30-65(55)$ & $30-65(55)$ & \\
\hline \multicolumn{4}{|l|}{ EuroSCORE II } \\
\hline Mean \pm SD & $2.6 \pm 1.8$ & $1.9 \pm 1.4$ & $0.033 \ddagger *$ \\
\hline Min-Max (Median) & $0.9-7.8(2.1)$ & $0.9-11.2(1.3)$ & \\
\hline
\end{tabular}

LVEF indicates left ventricular ejection fraction; BMI, body mass index. $* P<.05 ; \nmid P<.01 ; \ddagger$ Student $t$ test; $\S$ Yates continuity correction.

SD: Standart deviation

\section{Study Protocol}

We have collected data of adult patients were electively operated by the single surgical team between January 2015 and October 2016. Patients with anemia and low platelet counts $(\mathrm{Hb}<12 \mathrm{~g} / \mathrm{dL}$ or Hct $<36 \%$ and platelets $<140.000 /$ $\mathrm{mL}$ ) were excluded from the study, leaving a total number of 138 cases. We aimed not to transfuse all the patients meeting the preoperative criteria. The minimum threshold values for
Table 2. Distribution of Cases

\begin{tabular}{lcc}
\hline Operation, $\mathrm{n}(\%)$ & Transfusion (-) & Transfusion $\left(^{+}\right)$ \\
\hline Coronary artery bypass grafting & $80(\% 81.6)$ & $31(\% 77.5)$ \\
Valve replacement & $10(\% 10.2)$ & $2(\% 5)$ \\
Aortic surgery & $5(\% 5.1)$ & $2(\% 5)$ \\
Combined surgery & $3(\% 3.1)$ & $5(\% 12.5)$ \\
Total & $98(100)$ & $40(100)$
\end{tabular}

transfusion were $\mathrm{Hb}<6 \mathrm{~g} / \mathrm{dL}$, Hct $<18 \%$. During the cardiopulmonary bypass $(\mathrm{CPB})$, transfusions were done based on these threshold values. In peri/postoperative period, no cutoff hemoglobin and hematocrit values were kept in mind and transfusion decision was based on clinical and hemodynamic parameters such as persistent hypotension or tachycardia, hyperlactatemia, low urine output and anemic symptoms. Patients that were transfused in this period were evaluated under transfusion (+) group, and the rest of the patients were transfusion (-) group. The study protocol was approved by Siyami Ersek Thoracic and Cardiovascular Surgery Training and Research Hospital Ethics Committee. Informed consent was obtained from all patients.

\section{Operative Technique}

All patients in the study were operated with median sternotomy. After heparinization and cannulation, $\mathrm{CPB}$ was started. In patients which ascending aortic surgery was performed, total circulatory arrest (TCA) for open distal anastomosis was applied $\left(18^{\circ} \mathrm{C}\right)$ [Kaplan 2015]. Topical cooling was not performed in any of the operations. Except for the cases which were performed under TCA, during CPB, hypothermia $\left(<34^{\circ} \mathrm{C}\right)$ was avoided. Thus, the negative effect of hypothermia on coagulation was avoided.

Induction of anesthesia was done cautiously to avoid hypotension and unnecessary fluid infusion. After induction, arterial blood gas tests were performed frequently during the cardiopulmonary bypass (every 20 minutes) to closely monitor the hemoglobin levels. Hypervolemia was managed with intravenous diuretics (furosemide $10-20 \mathrm{mg}$ ) if necessary.

\section{Perioperative and Postoperative Parameters}

Hemoglobin and hematocrit levels in serial arterial blood gases withdrawn at the time of induction, at the beginning, during, and at the end of CPB were recorded. In addition, hemoglobin and hematocrit levels on operation day, postoperative 6-8 days (discharge), and 1 week after discharge (postoperative 14-16 days) were also recorded and compared between the two groups. Blood urea nitrogen (BUN) and creatinine levels were also assessed preoperatively and postoperatively.

In cardiac surgical patients, $1.5 \mathrm{~mL} / \mathrm{kg} / \mathrm{h}$ fluid replacement is appropriate postoperatively. In our study, mean body weight was 78 kilograms and the patients in our intensive care unit were infused with $100-150 \mathrm{~mL} / \mathrm{h}$ fluid.

In the first 24 hours in the intensive care unit, patients' drainage, 24-hours urine output, awakening and extubation 
Table 3. Distribution of the Descriptive Features

\begin{tabular}{lccc}
\hline & $\begin{array}{c}\text { Transfusion }(+) \\
(\mathrm{n}=40)\end{array}$ & $\begin{array}{c}\text { Transfusion }(-) \\
(\mathrm{n}=98)\end{array}$ & $P$ \\
\hline Awakening, h & & & \\
Mean \pm SD & $7.6 \pm 5.4$ & $6.4 \pm 2.1$ & $.202^{*}$ \\
Min-Max (Median) & $3-38(6.5)$ & $1.5-14(6)$ & \\
Extubation, h & & & \\
Mean \pm SD & $10.7 \pm 6.1$ & $9.32 \pm 2.61$ & $.326^{*}$ \\
Min-Max (Median) & $5-44(9)$ & $5-17(9)$ & \\
CPB time, min & & & \\
Mean \pm SD & $124.9 \pm 60.3$ & $130.9 \pm 34.1$ & $.601^{*}$ \\
Min-Max (Median) & $29-371(130)$ & $40-242(126)$ & \\
Cross-clamp time, min & & & $.305^{*}$ \\
Mean \pm SD & $92.6 \pm 46.2$ & $95.8 \pm 31.3$ & \\
Min-Max (Median) & $11-306(85.5)$ & $23-212(91)$ & \\
Stay in ICU, d & & & \\
Mean \pm SD & $1.3 \pm 0.8$ & $1.1 \pm 0.4$ & $.375^{*}$ \\
Min-Max (Median) & $1-4(1)$ & $1-3(1)$ & \\
Stay in hospital, d & & & \\
Mean \pm SD & $8.8 \pm 3.9$ & $8.4 \pm 4.4$ & $.638^{*}$ \\
Min-Max (Median) & $6-25(8)$ & & \\
\hline
\end{tabular}

ICU indicates intensive care unit; SD, Standart deviation; CPB, cardiopulmonary bypass.

*Mann-Whitney U Test

times, and lactate and bilirubin levels in arterial blood gases were recorded.

\section{Primary and Secondary Endpoints}

Among the patients enrolled in the study, we compared 30-day mortality between the two groups as our primary outcome. Prevalence of perioperative and postoperative 30-day morbidity (myocardial infarction, cerebrovascular incident, respiratory and infectious morbidity, renal and hepatic dysfunction and arrhythmia [postoperative atrial fibrillation in this study]) were compared as secondary outcomes.

Awakening and extubation times, days in intensive-care, follow-up, and discharge times were also present among the studied parameters.

\section{Statistical Analysis}

For statistical analysis NCSS (Number Cruncher Statistical System) 2007 program (Kaysville, Utah, USA) was used. Data were analyzed using descriptive statistical methods (mean, standard deviation, median, frequency, rate, minimum, maximum) as well as using Student $t$ test in the twogroup comparisons of parameters of the normal distribution of quantitative data and using Mann-Whitney $\mathrm{U}$ in the twogroup comparisons of parameters in abnormal distribution.
For the comparison of qualitative data, Fisher exact test, and Yates correction continuity test (Yates corrected chisquare) were used. The repeated measures (analysis of variance for repeated measurements) test was used in the comparison of parameters with normal distribution within each group and the adjusted Bonferroni test was used to compare the two groups.

For evaluation of the relations between parameters, Spearman correlation analysis was used. $P<.01$ and $P<.05$ values were evaluated as significant.

\section{RESULTS}

In our study, $71 \%$ of patients $(\mathrm{n}=98)$ did not receive blood and blood products while 29\% $(\mathrm{n}=40)$ were transfused. Demographic and preoperative features were compared (Table 1).

\section{Perioperative and Postoperative Care}

Except for patients who were operated under total circulatory arrest, mean temperature of procedures was $34.2 \pm 0.5^{\circ} \mathrm{C}$ $\left(34-36^{\circ} \mathrm{C}\right)$. Patients' awakening, extubation time, CPB period, cross-clamp time, and days in ICU and hospital were recorded. These data were compared and there was no statistically significant difference between the two groups $(P>.05)$ (Table 3$)$.

In the perioperative period, arterial blood gases were obtained at the induction of anesthesia (Hct1), at the beginning (Hct2), during (Hct3), and at the end of CPB (Hct4). The hematocrit values were compared. The hematocrit value of arterial blood gas taken during the induction was found to be higher than the hematocrit value in others following arterial blood gases in both groups (Table 4).

\section{Regaining the Blood in Oxygenator and Arterial Line}

After cessation of the cardiopulmonary bypass, venous volume in the reservoir is infused to the patient, with 350-500 $\mathrm{mL}$ of volume (Ringer's lactate solution or $0.9 \% \mathrm{NaCl}$ ) taken in order to obtain the patient's blood left in the arterial line and in the oxygenator chamber. After infusion of this volume, we took a sample from the artery line itself to assess hematocrit levels. We found hematocrit levels between 17.4-25.7\%. With this technique, patients with hematocrit levels between $23-24 \%$ at the time of $\mathrm{CPB}$ cessation showed hematocrit levels between $28-30 \%$ at the early postoperative period.

\section{Postoperative 24-Hour Follow-Up}

Thoracic and mediastinal tube drainage, urine output, lactate, and bilirubin values were compared between the two groups for the first 24 hours in the intensive care unit. There were no significant differences for urine output and bilirubin values $(P>.05)$. Mean drainage was $705 \mathrm{~mL}(250-1350$ $\mathrm{mL} \mathrm{min} / \mathrm{max}$ ) in the transfusion (+) group, and $510 \mathrm{~mL}(100$ $1400 \mathrm{~mL} \mathrm{~min} / \mathrm{max}$ ) in the transfusion (-) group. This difference was not statistically significant $(P>.05)$. Lactate levels were significantly lower in the transfusion (-) group $(P=.005$, $P<.01)$. This finding means that the hemodynamics of the patients remained stable and there was no sign of malperfusion in the transfusion (-) group. 
Table 4. Evaluation of Hematocrit Results in Perioperative Serial Arterial Blood Gases

\begin{tabular}{|c|c|c|c|c|}
\hline Hct 1 & $\begin{array}{l}\text { Min-Max } \\
\text { (Median) }\end{array}$ & $36-51.3(42.4)$ & $31.1-48.8(41.7)$ & \\
\hline \multirow[t]{2}{*}{ Hct 3} & Mean \pm SD & $28.2 \pm 3.0$ & $28.2 \pm 3.6$ & .911 \\
\hline & $\begin{array}{l}\text { Min-Max } \\
\text { (Median) }\end{array}$ & $21.9-35.7(28.5)$ & $23.1-39.8(27.6)$ & \\
\hline \multirow[t]{2}{*}{ Hct 4} & Mean \pm SD & $32.9 \pm 3.7$ & $33.1 \pm 3.5$ & .846 \\
\hline & Intergroup comparisons & Difference $($ Mean $\pm S D)$ & $P \S$ & Difference (Mean $\pm S D$ ) \\
\hline Hct 1 - Hct 2 & .001|| & $-11.1 \pm 4.4$ & .001|| & $-11.1 \pm 5.4$ \\
\hline Hct $1-$ Hct 3 & .001|| & $-13.9 \pm 4.1$ & .001|| & $-13.3 \pm 4.5$ \\
\hline Hct 1 - Hct 4 & .001|| & $-9.2 \pm 4.5$ & .001|| & $-8.4 \pm 5.1$ \\
\hline
\end{tabular}

Hct indicates hematocrit; CPB, cardiopulmonary bypass.

$* P<.05 ; \nmid$ Student $t$ test; $\ddagger$ Repeated measures test; §Paired samples test; ||$P<.01$.

Hct1: Induction of anesthesia. Hct2: Initiation of CPB. Hct3: During CPB. Hct4: End of CPB.

SD: Standart deviation.

\section{Hemoglobin Values}

When the preoperative hemoglobin levels were compared, there was no statistically significantly difference between hemoglobin levels of the patients in the transfusion (-) group and transfusion $(+)$ group $(\mathrm{p}=0.707)$ (Table 5).

Hemoglobin levels of operation day, the day of discharge (postoperative 6-8 days), and the first week after discharge were compared between the two groups and there was no statistically significant difference $(P>.05)$ (Table 5).

At the time of discharge, hemoglobin levels were between $7.5-12.1 \mathrm{~g} / \mathrm{dL}$ in the transfusion $(+)$ group and between 7.63$11.5 \mathrm{~g} / \mathrm{dL}$ in the transfusion (-) group. When comparing the hemoglobin levels of the discharge time and routine check-up 1 week after discharge, hemoglobin levels were statistically significantly higher in the check-up $(P=.001 ; P<.01)$ (Table 5).

\section{Blood and Blood Products Transfusion}

In the transfusion (+) group, packed red blood cells (mean 2 units, $\min / \max 0-8$ units.), whole blood (mean 0.28 unit, $\mathrm{min} / \mathrm{max} 0-4$ units) and fresh frozen plasma (mean 2.07 units $\mathrm{min} / \mathrm{max} 0-11$ units) were transfused.

\section{Morbidity}

Arrhythmias (atrial fibrillation, atrial tachycardia), infections, renal failure, revision, allergy, and hypoxia were observed as complications (Table 6). Amiodarone was given to the patients who developed atrial fibrillation (AF). Sinus rhythm was established after amiodarone treatment in all of these patients.

One patient developed hypoxia and symptoms did not regress with inhaler therapy. Hemoglobin value of this patient was found to be $6.3 \mathrm{gr} / \mathrm{dL}$. After transfusion of one pack of red blood cells, saturation rose to normal levels and symptoms disappeared. In 2 cases blurred vision was observed (Table 6). In these patients, low molecular weight heparin was added to the treatment, and patients' symptoms were regressed.

There was no statistically significant difference in terms of morbidity between the two groups $(P>.05)$ (Table 6$)$.

\section{Renal Dysfunction}

There was no statistically significant difference in preoperative and postoperative creatinine levels for both groups. Preoperative and postoperative BUN levels were also compared. 
Table 5. Evaluation of the Definitive Characteristics According to the Presence of Transfusion

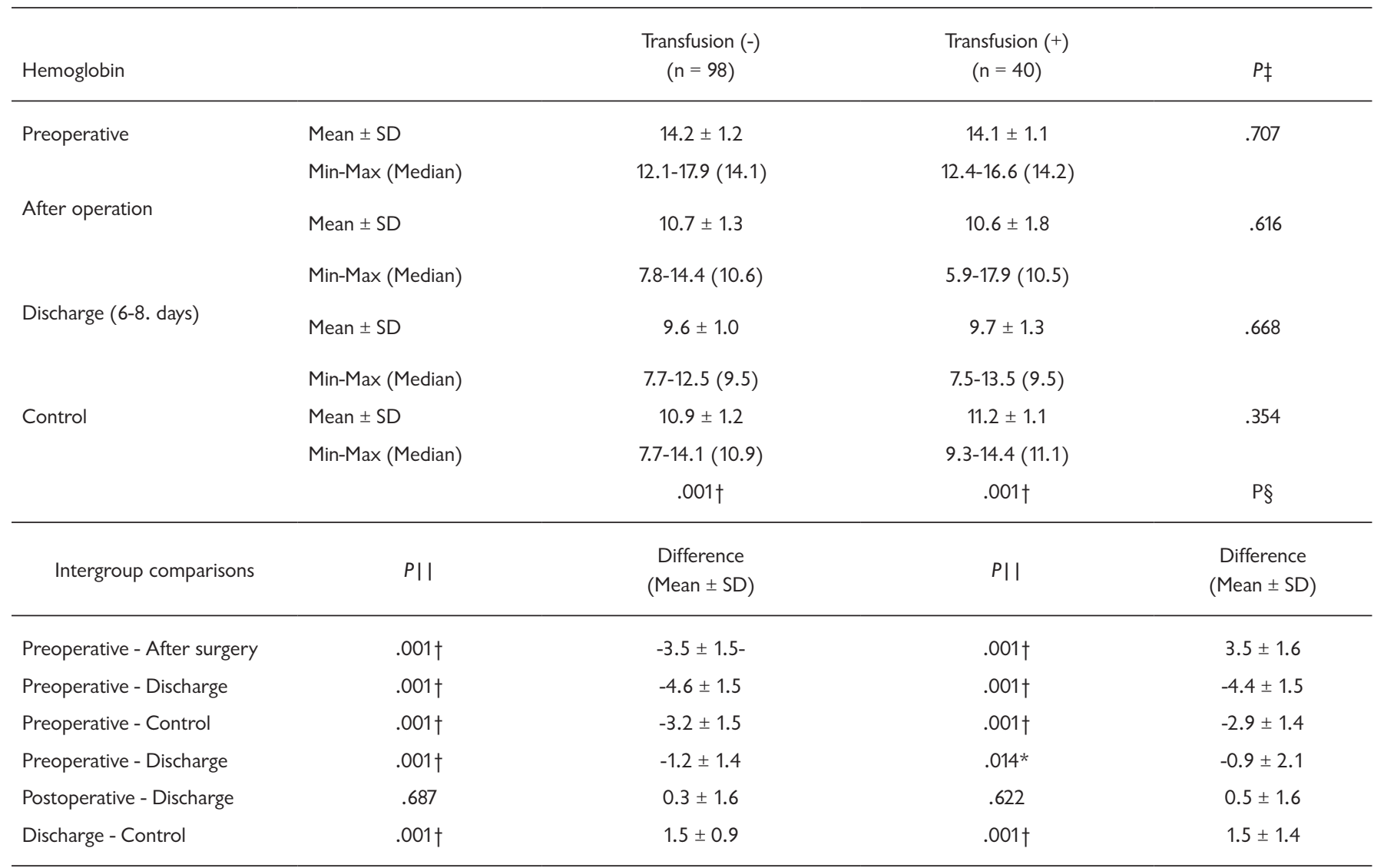

$* P<.05 ; \nmid P<.01 ; \ddagger$ Student $\mathrm{t}$ test; $\S$ Repeated measures test; | | Paired samples test.

SD: Standart deviation.

There was no difference in the transfusion (+) group but in the transfusion (-) group, preoperative levels were statistically significantly higher than postoperative levels $(P=.008$; $P<.05)$ (Table 7).

\section{Mortality}

When comparing mortality rates between groups, the transfusion (-) group showed $1 \%$ mortality (1 patient) and the transfusion (+) group showed $2.5 \%$ mortality (1 patient); however, the difference was not statistically significant $(\mathrm{P}>.05)$.

\section{Hematocrit Threshold for Restrictive Transfusion}

We observed that patients hemodynamically and clinically tolerated the hematocrit value of $18.8 \%$ under cross-clamp, $24 \%$ at the end of CPB, $21.9 \%$ in the intensive care, and $21.8 \%$ during service follow-up.

\section{DISCUSSION}

Anemia occurring after surgery is caused by perioperative and postoperative bleeding and causes hypoxia. To avoid this risk, we must maintain the hemostasis and respect the tissue at each stage of the surgery. In case of major bleeding that occurs after surgery, if it begins to affect the hemodynamics, additional measures like starting vasoconstrictor infusions, applying protamine or tranexamic acid, or early revision for bleeding may be required. Despite all these measures, allogeneic blood transfusion (red cells, platelets, fresh frozen plasma) may be needed. However, these blood products predispose more co-morbidities including thromboembolism and renal dysfunction [Bennett-Guerrero 2010].

In cardiac surgery, total blood and blood products are transfused at a rate of $10-15 \%$ (15 million units of packed red blood cells per year) and it increases with the size and complexity of the surgery performed [Ranucci 2013]. This amount of blood and blood products causes the transfusion to become a quality indicator in cardiac surgery [Ferraris 2011].

In one study, 43.529 adult cardiac surgery patients from 25 hospitals in Australia were evaluated. Transfusion practice showed no difference between the surgical teams in the same center, but the difference between centers was found to be statistically significant [McQuilten 2014]. Our cases were operated by one surgical team who followed the same principles during surgery, intensive care, and service follow-up. 
Table 6. Evaluation of the Characteristics and Morbidity According to the Presence of Transfusion

\begin{tabular}{lcccc}
\hline \multirow{4}{*}{ Arrhythmia } & & $\begin{array}{c}\text { Transfusion }(+) \\
(\mathrm{n}=40)\end{array}$ & $\begin{array}{c}\text { Transfusion }(-) \\
(\mathrm{n}=98)\end{array}$ & $P$ \\
\hline \multirow{4}{*}{ Infection } & Yes & $14(35.0)$ & $25(25.5)$ & $.360^{*}$ \\
& No & $26(65.0)$ & $73(74.5)$ & \\
\multirow{3}{*}{ Kidney failure } & Yes & $7(17.5)$ & $12(12.2)$ & $.589 *$ \\
& No & $33(82.5)$ & $86(87.8)$ & \\
Revision & Yes & $1(2.5)$ & $1(1.0)$ & $.497 \dagger$ \\
& No & $39(97.5)$ & $97(99.0)$ & \\
Allergy & Yes & $4(10.0)$ & $3(3.1)$ & $.193 \dagger$ \\
& No & $36(90.0)$ & $95(96.9)$ & \\
Hypoxia & Yes & $1(2.5)$ & - & $.290 \dagger$ \\
& No & $39(97.5)$ & $98(100.0)$ & \\
Blurred vision & Yes & - & $4(4.1)$ & $.323 \dagger$ \\
& No & $40(100)$ & $94(95.9)$ & \\
& Yes & $1(2.5)$ & $1(1.0)$ & $.531 \dagger$ \\
& No & $39(97.5)$ & $97(99.0)$ & \\
\hline
\end{tabular}

*Yates continuity correction; $†$ Fisher exact test.

On the other hand, the decision for transfusion is usually more subjective rather than objective and evidence-based. Even standard heart surgery operations such as coronary artery bypass surgery are done with various rates of transfusion (between 10-90\%) and in the majority of transfusion trials, high-quality evidence cannot be found due to regulatory restrictions and ethical reasons [Ferraris 2007]. On this topic, Senay and colleagues [Senay 2009] questioned if it is the patients or the physicians who cannot tolerate anemia in the preoperative and postoperative period. Sometimes the main reason for transfusion is the concern on the part of the physician rather than the patient's physiological requirements.

When we look at transfusion guidelines, during cardiopulmonary bypass and moderate hypothermia, it is indicated to transfuse when hemoglobin levels are $6 \mathrm{~g} / \mathrm{dL}$ or less. However, history of cerebrovascular disease, diabetes mellitus, and the risk of low cerebral oxygenation such as carotid artery stenosis, may require maintaining higher hemoglobin concentrations [Ranucci 2013; Ferraris 2011]. Even this information, shown in guidelines, should not be the only decisive factor in transfusion. In fact, the most reliable evidence in patients undergoing cardiac surgery for optimal blood management should be the patient's clinical condition, functional capacity, central venous pressure, arterial blood pressure, and heart rate during intraoperative and postoperative care follow-up, rather than a specific preoperative hemoglobin concentration [Ferraris 2015]. In this study, we operated patients who did not have anemia preoperatively. Although patients with preoperative anemia were not included in the study, we performed all the necessary studies for anemia etiology and then operated. When we encountered postoperative anemia, we put all our efforts into keeping patients hemodynamically stable, not just to raise $\mathrm{Hb}$ values. We performed transfusion based on patients' hemodynamic and clinical situations without specifying any target hematocrit and hemoglobin values.

In light of the data we obtained, we identified hematocrit values of $18.8 \%$ during perioperative, $21.9 \%$ during postoperative, and $21.8 \%$ during service follow-up as threshold values tolerated by patients. In addition, lactate levels did not show statistically significant difference between the two groups. This data shows that the patients who did not receive any blood or blood products were not hemodynamically compromised.

In the literature, in addition to a study about liberal and restrictive transfusions of blood and blood products, studies involving Jehovah's Witnesses (JW) give results related to the allogeneic blood transfusions in the perioperative period [Murphy 2015; Patel 2015; Bhaskar 2010; Bernal 2006]. In one study, a total number of 49 Jehovah's Witnesses underwent open heart surgery at a single center in 3 years and did not receive any blood and blood products. They were compared in terms of mortality and morbidity with other patients and there was no significant difference between the two groups, parallel to our findings [Bhaskar 2010]. On the other hand, one of the main differences of our study is that our patients had no hematological or ethical reasons for the need of non-transfusion open heart surgery.

In a study by Pattakos and colleagues [Pattakos 2012], 322 Jehovah's Witness patients who underwent open heart surgery were followed for 20 years. In early periods, JW patients had better outcomes but there was no significant difference in survival between the two groups at the end of 20 years. This data confirms other studies and shows that open heart surgery without transfusion can be performed safely in Jehovah's Witnesses [Marshall 2012].

The prevalence of transfusion-acquired infections such as West Nile Virus, HCV, HIV, and prion diseases has also focused attention on the use of liberal blood and blood products in other patient groups in open heart surgery [Bhaskar 2010; Bernal 2006].

In a meta-analysis on liberal and restrictive transfusions with a total number of 3,352 patients, postoperative 30-day mortality and postoperative myocardial infarction, pulmonary morbidity, acute kidney injury, infectious morbidity, and rate of cerebrovascular events were examined [Patel 2015]. Randomized controlled trials in this meta-analysis showed that the liberal transfusion group had higher mortality than in the restrictive transfusion group. However, this difference was not statistically significant.

But in observational studies related to transfusion in adult open heart surgery, transfused patients had increased mortality and morbidity rates compared to those who were not transfused [Murphy 2007; Koch 2008]. In contrast, there was no statistically significant difference in mortality and morbidity between our groups. In our transfusion (+) group, the number of transfused blood and blood products did not increase our mortality or morbidity rates. 
Table 7. Evaluation of Laboratory Results and Transfusion

\begin{tabular}{|c|c|c|c|c|c|}
\hline & & & $\begin{array}{c}\text { Transfusion }(+) \\
(n=40)\end{array}$ & $\begin{array}{c}\text { Transfusion }(-) \\
(n=98)\end{array}$ & $P^{*}$ \\
\hline \multirow{2}{*}{ Creatinine } & & Min-Max (Median) & $0.6-9.9(0.9)$ & $0.6-2(0.9)$ & \\
\hline & & Mean \pm SD & $0.8 \pm 0.2$ & $0.9 \pm 0.2$ & .390 \\
\hline \multirow[t]{4}{*}{ BUN } & Preoperative & Mean \pm SD & $17.5 \pm 9.4$ & $16.3 \pm 5.8$ & .364 \\
\hline & & Min-Max (Median) & $8-65(16)$ & $8-49(15)$ & \\
\hline & & Mean \pm SD & $15.0 \pm 5.6$ & $15.0 \pm 4.5$ & .973 \\
\hline & Postoperative & Min-Max (Median) & 6-39 (14) & $6-35(15)$ & \\
\hline
\end{tabular}

BUN indicates blood urea nitrogen.

*Student $\mathrm{t}$ test; $\nmid$ Paired samples test. $¥ P<.05$.

$\mathrm{SD}$, Standart deviation.

\section{Conclusion}

In common practice, surgeons and intensive-care physicians are prone to make transfusion, especially in cardiac surgery patients. Although the patient does not have a need for blood transfusion, the physician may need it. The important thing is to be aware of the adverse effects caused by blood and blood product transfusion and feasibility of performing open heart surgery without transfusion. Close monitoring of these patients in the intensive care and service is also possible.

When we look at the literature about open heart surgery without transfusion, significant portion of the studies consist of Jehovah's Witnesses. This is the most important difference between our study and literature.

In addition, studies mainly examined the transfusion of packed red blood cells and whole blood. In our study, neither blood (red cells, whole blood) nor blood products (fresh frozen plasma, platelets) were transfused.

We were able to tolerate low hemoglobin values for patients who are hemodynamically unaffected, without any end-organ dysfunction during clinical follow-up and biochemical screenings, with adequate urine output, low lactate levels and good functional status; in summary for patients who can tolerate low hemoglobin levels.

In this study, we performed bloodless surgery with a $71 \%$ rate. In the initial phase of the study, the rate was lower $(61 \%)$ because of surgeons' practical differences, while the rate in the last period was close to $86 \%$. In the near future, we aim for a rate close to $100 \%$ in elective cases.

With our data, we think that a large spectrum of open heart surgery cases can be done safely with good results without the use of blood and blood products in patients who have no ethical or medical contraindications for transfusion. Decisions of transfusion must be made by the patient's physiological requirements, not the physician's unnecessary worries. It should not be forgotten that blood transfusion is an organ transplantation.

\section{Study Limitations}

We tried to create a common practice between surgeons, anesthetists, perfusionists, and intensivists, and we can say that we have reached this goal significantly. But sometimes, especially in night shifts, rare, unnecessary blood transfusion arising from the physician's concerns occurs. We hope to prevent these improper practices in time via the common practice we developed and use.

\section{REFERENCES}

Bennett-Guerrero E, Zhao Y, O'Brien SM, et al. 2010. Variation in use of blood transfusion in coronary artery bypass graft surgery. JAMA 304:1568-75.

Bernal JM, Naranjo S, Trugeda M, Sarralde A, Diago C, Revuelta JM. 2006. Cardiac Surgery in Jehovah's Witnesses. Experience in Santander, Spain. Revista Española de Cardiología (English Edition) 59:507-9.

Bhaskar B, Jack RK, Mullany D, Fraser J. 2010. Comparison of outcome in Jehovah's Witness patients in cardiac surgery: an Australian experience. Heart Lung Circ 19:655-9.

Ferraris VA, Ferraris SP, Saha SP, et al. 2007. Perioperative blood transfusion and blood conservation in cardiac surgery: The Society of Thoracic Surgeons and The Society of Cardiovascular Anesthesiologists Clinical Practice Guideline. Ann Thorac Surg 83:27-86.

Ferraris VA, Brown JR, Despotis GJ, et al. 2011. 2011 update to the Society of Thoracic Surgeons and the Society of Cardiovascular Anesthesiologists blood conservation clinical practice guidelines. Ann Thorac Surg 91:944-82.

Ferraris VA. 2015. Blood transfusion in cardiac surgery: who should get transfused? Lancet Haematol 2:510-11. 
Kaplan M, Temur B, Can T, Abay G, Olsun A, Aydogan H. 2015. Open distal anastomosis technique for ascending aortic aneurysm repair without cerebral perfusion. Heart Surg Forum 18: E124-8.

Koch CG, Li L, Duncan AI, et al. 2006. Morbidity and mortality risk associated with red blood cell and blood-component transfusion in isolated coronary artery bypass grafting. Crit Care Med 34:1608-78.

Koch CG, Li L, Sessler DI, et al. 2008. Duration of red-cell storage and complications after cardiac surgery. N Engl J Med 358:1229-39.

Marshall L, Krampl C, Vrtik M, et al. 2012. Short-term outcomes after cardiac surgery in a Jehovah's Witness population: an institutional experience. Heart Lung Circ 21:101-4.

McQuilten ZK, Andrianopoulos N, Wood EM, et al. 2014. Transfusion practice varies widely in cardiac surgery: Results from a national registry. J Thorac Cardiovasc Surg 147:1684-90.

Murphy GJ, Reeves BC, Rogers CA, Rizvi SI, Culliford L, Angelini GD. 2007. Increased mortality, postoperative morbidity, and cost after red blood cell transfusion in patients having cardiac surgery. Circulation 116:2544-52.
Murphy GJ, Pike K, Rogers CA, et al. 2015. Liberal or restrictive transfusion after cardiac surgery. N Engl J Med 372:997-1008.

Patel NN, Avlonitis VS, Jones HE, Reeves BC, Sterne JA, Murphy GJ. 2015. Indications for red blood cell transfusion in cardiac surgery: a systematic review and meta-analysis. Lancet Haematol 2: e543-53.

Pattakos G, Koch CG, Brizzio ME, et al. 2012. Outcome of patients who refuse transfusion after cardiac surgery: a natural experiment with severe blood conservation. Arch Intern Med 172:1154-60.

Pulido JN. 2015. Transfusion strategies in cardiac surgery: More pieces to the puzzle, more questions to be answered. J Thorac Cardiovasc Surg 150:1320-1

Ranucci M, Baryshnikova E, Castelvecchio S, Pelissero G. 2013. Major bleeding, transfusions, and anemia: the deadly triad of cardiac surgery. Ann Thorac Surg 96:478-85.

Senay S, Toraman F, Karabulut H, Alhan C. 2009. Is it the patient or the physician who cannot tolerate anemia? A prospective analysis in 1854 non-transfused coronary artery surgery patients. Perfusion 24:373-80. 